\title{
De la utilidad del olvido para la vida
}

\section{About the Usefulness of Oblivion for Life}

\author{
Pilar GILARDI $^{*}$
}

IIH, Universidad Nacional Autónoma de México

\begin{abstract}
Resumen: Este artículo se propone pensar en el concepto de olvido que Nietzsche desarrolla en su Segunda consideración intempestiva desde una perspectiva ontológica, lo cual implicará tomar como guía la lectura de Martin Heidegger. Ésta supone, por un lado, reconocer la polisemia del fenómeno del olvido, y por el otro, reflexionar sobre la íntima relación entre conceptos fundamentales de la filosofía nietzscheana, como vida, olvido y voluntad de poder. Comprender estos términos desde una perspectiva ontológica requiere revisarlos a partir de su estatuto originario.
\end{abstract}

Palabras clave: Heidegger, Nietzsche, olvido, vida, voluntad de poder.

АвsтRACT: This paper suggests we think about the concept of forgetfulness that Nietzsche develops in his Use and Abuse of History for Life from an ontological perspective. This task implies taking a Heideggerian interpretation of Nietzsche. It is necessary, on one hand, to recognize the polysemy of the phenomenon of forgetfulness itself, and on the other hand, to ponder the intimate relationship between certain fundamental concepts in Nietzschean philosophy, such as life, forgetfulness and the will to power. Comprehending such notions from an ontological perspective entails backtracking them to their original statute.

KeYwords: Heidegger, Nietzsche, forgetfulness, life, will to power.

\footnotetext{
* Investigadora del Instituto de Investigaciones Históricas de la UNAM, Circuito Mario de Cueva S/N, Ciudad Universitaria, CDMX, pilargilardi@gmail.com.
} 


\section{Introducción}

Los años que Heidegger dedica a la lectura de Nietzsche (1936-1946) son convulsos. El extenuante cuerpo a cuerpo con los textos nietzscheanos, la profunda crisis iniciada en 1938, el final de la guerra y la agobiante situación personal en la que había caído (Volpi, 2007, 106), dan testimonio de una confrontación de talante particularmente trágico, que se distingue del diálogo con filósofos anteriores, característico de la filosofía heideggeriana en su totalidad. ${ }^{1}$ El nombre Nietzsche se convierte en una suerte de hilo conductor y término de referencia para pensar de modo radical la negatividad inherente al ser, que sin duda había comenzado ya en la lección inaugural de 1929, ¿Qué es metafísica?, o De la esencia de la verdad, de 1930. El problema de la negatividad, y por ende los reiterados intentos de pensar el ser en su sustraerse y rehusarse, llega a ocupar una posición cada vez más importante en la reflexión de Heidegger (Volpi, 2007, 100).

En los últimos años dedicados a Nietzsche, Heidegger ofrece un curso que rompe en cierta medida la secuencia con los anteriores. Si su interpretación se había caracterizado por señalar que lo esencial del filósofo de Weimar se encontraba en su pensamiento de madurez, en 1938-1939 regresa a un escrito de juventud: De la utilidad y los inconvenientes de la historia para la vida. Segunda consideración intempestiva (Nietzsche, 2011 [1874]). El análisis de este texto, que ahora nos llega en forma de notas, ${ }^{2}$ le permitirá a Heidegger afirmar que ahí está ya el germen de los conceptos fundamentales de la filosofía nietzscheana, en

\footnotetext{
1 Heidegger conoció a profundidad tanto el pensamiento de Nietzsche como la situación y los avatares de la edición de su obra. Si toda la filosofía heideggeriana debe comprenderse bajo el signo de la apropiación, el caso de Nietzsche es aún más radical, quizá sólo comparable con la interpretación que el joven Heidegger hizo de Aristóteles. Es fundamental tener esto en mente porque dicha apropiación, que de manera inevitable conlleva confrontación, no busca fidelidad de ninguna manera, sino volver a pensar lo esencial de ese pensamiento. Sobre esta cuestión y la peculiaridad e intensidad de la relación entre Heidegger y Nietzsche, véanse Volpi $(2007,93-117)$ y Leyte $(2005,207-210)$.

2 Durante el proceso de edición de lo que serán Nietzsche I y II, que se publicarán en 1961, se recogen los cinco cursos universitarios de 1936 a 1940 . Heidegger decide dejar fuera el seminario sobre la Segunda consideración intempestiva (1938-1939) debido al carácter fragmentario del manuscrito. Los textos editados por Heidegger formarán los volúmenes 6.1 y 6.2 de la Gesamtausgabe (GA) — reunidos en Heidegger (2017)_. En 2003, la lectura heideggeriana sobre la Segunda consideración intempestiva se publicará como volumen 46 de la GA (Heidegger, 2003). A propósito de los cursos de Heidegger dedicados a Nietzsche y su publicación, véase Volpi $(2007,105-108)$. A partir de ahora asumimos las traducciones de los textos de Heidegger, excepto en el caso de que no exista tal.
} 
particular la noción de $v i d a,{ }^{3}$ que a sus ojos anuncia el nacimiento de la voluntad de poder, noción clave en su interpretación de Nietzsche.

En este artículo procederemos de modo cronológicamente inverso al que llevó a cabo Heidegger en su apropiación nietzscheana, pues tomamos como punto de partida la Segunda consideración intempestiva y retrotraemos el análisis al horizonte interpretativo de la voluntad de poder. Sin obviar el lugar central que juegan en las reflexiones que llevamos a cabo, las lecciones de 1929-1930: Los conceptos fundamentales de la metafisica. Mundo, finitud y soledad, consagradas a pensar la animalidad del animal. La figura del animal, tanto en Nietzsche como en Heidegger, ocupa un lugar central en su reflexión sobre la vida. En nuestro texto, el animal aparece como alegoría de la vida y del olvido que ésta requiere para poder llevarse a cabo.

De tal forma, esta investigación parte de la interpretación ontológica del vínculo ineludible entre vida y voluntad de poder, caracterizado por una suerte de olvido constitutivo. Para indagar en este nexo, en un primer momento presentamos la comprensión heideggeriana de la voluntad de poder como carácter fundamental del ente. En segundo lugar, analizamos el sitio emblemático de la vida como forma de la voluntad de poder, para, por último, pensar con Nietzsche cómo la condición de la acción, expresión de vida, es el olvido.

\section{La comprensión del ser como voluntad de poder}

La comprensión de la filosofía como apropiación se hace patente de manera singular en el Nietzsche de Heidegger. Las tesis fundamentales del pensamiento del filósofo de la voluntad de poder y el eterno retorno son retrotraídas al ámbito de la pregunta fundamental de la filosofía, esto es, la pregunta por el ser. De manera cada vez más acuciosa esta cuestión hará evidente la negatividad originaria de aquello sobre lo que pregunta y determinará todo lo pensado por Heidegger. Justamente, la voluntad de poder será pensada a partir de esta negación constitutiva, de la que el olvido aparecerá como rasgo fundamental. Así, es posible hacer una lectura del olvido que reconoce un doble empleo del término: uno óntico, en el que es posible considerar el olvido en relación con la memoria y el recuerdo, y

3 En los apuntes reunidos en el tomo 46 GA, Heidegger reitera la importancia crucial del concepto vida a lo largo del pensamiento de Nietzsche y advierte en esta noción un antecedente de la voluntad de poder. 
otro filosófico-ontológico, en el que el olvido no refiere a una acción particular, sino a un modo de ser (Volpi, 1988, 23). ${ }^{4}$

De la comprensión heideggeriana del ser como aquello que desaparece en el aparecer - esa retracción que acompaña como una sombra a todo ente ${ }^{5}$-, es posible desprender una interpretación original del olvido. El carácter negativo de este fenómeno se hace patente en sus raíces etimológicas. En latín, oblivisci es un verbo deponente. ${ }^{6}$ Más allá de lo que significa esta afirmación en términos gramaticales, es interesante reparar en los sinónimos del término deponer: separar, apartar, privar, dejar. De manera paradójica, también: afirmar, atestiguar, aseverar.

En los apuntes del curso de 1938-1939, Heidegger ofrece un esbozo de las principales características del olvido, que se repetirán a lo largo de sus notas. Como es usual en su modo de proceder, empieza por observar que la etimología de la palabra Vergessen —olvidar- arroja luz sobre el asunto. Advierte que, aunque no podemos revelar simplemente la esencia de la cosa en cuestión a partir del significado de la palabra, si ésta es auténtica (y nunca lo es de manera accidental), podemos obtener un aprendizaje esencial de ella. ${ }^{7}$ Así las cosas señala:

\footnotetext{
4 La fórmula, como está escrita, la tomamos de Volpi (1988), pero él la utiliza para expresar lo propio de las virtudes intelectuales que Heidegger toma del libro VI de la Ética nicomáquea de Aristóteles.

5 «La filosofía [...] es la encargada de revelar que además de ese predominio óntico, que es lo único que aparece a la vista, se esconde el ser, pero no como algo que finalmente y después de un esfuerzo analítico, de naturaleza moral o cognoscitiva, vaya a aparecer descubierto, sino precisamente como ese encubrimiento que resulta a la manifestación de cada cosa: si lo ente es lo que aparece, el ser es lo que desaparece en ese aparecer, esa retracción que acompaña como una sombra toda visión, pero que es la única sombra que merece el nombre de fenómeno" (Leyte, 2007, 177-178).

6 «Hay que partir del verbo oblivisci, que es "deponente”, es decir, un verbo con forma pasiva pero significado activo. Esta cualidad formal se adecua bien al significado "olvidar", que también se sitúa como una especie de medium entre actividad y pasividad» (Weinrich, 1999, 16).

7 "Vergessen" - das Wort; (zwar aus der Wortbedeutung nicht ohne weiteres das Wesen der Sache herauszuklauben, andererseits das Wort —als echtes — nie zufällig und daher aus den richtigen Anweisungen zu entnehmen, gesetzt, da $\beta$ wir schon den Blick auf die Sache haben und wenn es auch nur ein fragender ist)» (Heidegger, 2003, 37).
} 
a) ver-gessen-gezzen, desaparecido tempranamente del alemán; (en inglés to get), significa encontrar, conseguir, conservar. Ver-gessen- no conseguir, no conservar, no retener; lo olvidado es lo que no ha sido conservado, lo dejado, lo que se ha "ido".

b) Oblivisci- (oblino- manchar, difuminar, escribir sobre, tachar, borrar); también remover, no considerar algo más como real, lo olvidado está eliminado, "ido".

c) غ́ंı $\lambda \alpha v \theta \alpha ́ v \varepsilon \sigma \theta \alpha 1$ - pasar a otra cosa, hacia algo, dejar este "algo" pasar a lo

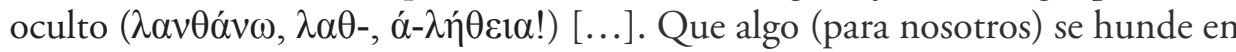
lo oculto. "Alejarse"- llevarse a uno mismo a una no relación, pero en el sentido griego (Heidegger, 2003, 30). ${ }^{8}$

En el texto que citamos de manera libre, junto al alemán antiguo Vergessen, Heidegger subraya el inglés forget, que formado a partir del verbo (to get significa "obtener", y en unión con el prefijo for, puede parafrasearse como "desobtener". Lo cual supone ya una determinación esencial del olvido. Inmediatamente después, el filósofo alemán, señala la etimología latina del término, en la que se expresa su especificidad: una suerte de exclusión, de eliminación, que indica también una supresión peculiar. Por último, como una sorpresa con la que él mismo se encuentra en el ejercicio deconstructivo del término, apunta entre signos de admiración el griego alétheia, noción clave en su filosofía. Olvidar, como "acción" que implica un dejar ir, dejar pasar a lo oculto, esto es, a lo que no se muestra, evoca el sentido de alétheia como "desocultamiento", y de "verdadero" como "desoculto". En efecto:

\footnotetext{
8 «a) ver-geseen- gezzen, im Deutschen früh untergegangen; (englisch to get) treffen, erlangen, halten. Ver-gessen- nicht erlangen, nicht halten, nicht-behalten; das Vergessene ist das Nichtgehaltene, das Ent-fallene, ist "weg".

b) oblivisci- (oblino- beschmieren, verschmieren die Wachstafel, darauf geschrieben- ausstreichen, auslöschen); medial sich weg wischen, für sich unwirklich machen, das Vergessene ist ausgelöscht, "weg”.

c) $\varepsilon ́ \pi \mathrm{r} \lambda \alpha v \theta \alpha ́ v \varepsilon \sigma \theta \alpha 1$ - auf etwas zu, dieses "sich" in das Verborgene ( $\lambda \alpha v \theta \alpha \dot{v} \omega \omega, \lambda \alpha \theta-$, $\alpha-\lambda \eta ́ \theta \varepsilon ı \alpha$ !) geraten lassen, weil und sofern man selbst dagegen verschlossen!, da $\beta$ (einem) etwas in das Verborgene weg-sinkt. "weg" -sich in den Unbezug bringen, aber griech.: sich selbst zugedeckt sein -in Bezug zu» (Heidegger, 2003, 37-38).
} 
Esta palabra cuyo primer elemento, $a$-, es sin lugar a dudas un prefijo de negación (alpha privativum), al que le sigue el elemento anexo -leth-, designa algo escondido, oculto, "latente" (en latín esta última, está emparentada con -lenth-), de forma que la verdad, por su significado literal, aparece - con Heidegger - como lo no escondido, no oculto, no "latente" (Weinrich, 1999, 20).

Como es sabido, el término alétheia servirá a Heidegger para señalar que "verdad" no designa una posición, sino el interno movimiento de llegar a aparecer, del cual son constituyentes tanto lo que se desvela o desoculta, como el velamiento y ocultamiento" (Leyte, 2005, 182). ${ }^{9}$ Así, la verdad no puede entenderse más como adaequatio intellectus et rei y su lugar no debe buscarse, como lo ha hecho la tradición, en el enunciado, ya que la verdad como desocultamiento es previa a ambas consideraciones y las posibilita.

Como lo indicamos en la introducción, la tarea que nos hemos propuesto —una interpretación ontológica del olvido a partir de la Segunda consideración intempestiva - necesita traer a colación la lectura que Heidegger hace de Nietzsche en los cursos de 1936 a 1940, que descansa en la consideración de la voluntad de poder como modo fundamental del ser. Sólo de esta manera podremos hacer relevante el vínculo entre voluntad de poder, vida y olvido, motivo de la reflexión presente.

Para el filósofo de la Selva Negra, la expresión voluntad de poder, ${ }^{10}$ por un lado, sirve de título para la obra filosófica capital que Nietzsche planeó y preparó durante años, sin llegar a consumarla; por el otro, es la denominación de lo que constituye el carácter fundamental de todo ente (Heidegger, 2017, 20). Que el

\footnotetext{
9 La cita continúa: «Porque a todo des-cubrimiento es inherente su encubrimiento. Pero este encubrimiento, como se seńaló más arriba, no es despreciable, sino lo más relevante. Igual que de una cosa es propia su sombra, y de lo que se puede ver de ella es también propio aquello que no se puede ver» (Leyte, 2005, 182).

10 El contacto de Heidegger con el Archivo Nietzsche, por quien fue contratado para la edición de la obra completa y las cartas del filósofo que se conservan en relación con este asunto, dan testimonio del conocimiento que tenía de la obra nietzscheana en su totalidad (Heidegger, 2017, 20-29; Volpi, 2007, 101-105). Por lo tanto, cuando refiere a la voluntad de poder, lo hace en el sentido que se encuentra en el propio Nietzsche: como título de una obra nunca concluida y como concepto fundamental de su pensamiento. Sobre el origen y la presencia de la voluntad de poder en la filosofía de Nietzsche, véase Aspiunza (2016, 443).
} 
carácter fundamental del ente se exprese con dicho término significa que cada ente, en tanto que es, es voluntad de poder (Heidegger, 2017, 29). Así, para Heidegger es posible afirmar:

La pregunta acerca de qué es el ente busca el ser del ente. Todo ser es, para Nietzsche, un devenir. Este devenir tiene, sin embargo, el carácter de la acción y de la actividad del querer. Pero la voluntad es, en su esencia, voluntad de poder. Esta expresión nombra aquello que Nietzsche piensa cuando pregunta la pregunta conductora de la filosofía $(2017,20)$.

Así, aunque en la representación común la voluntad se identifica con una facultad del alma, resulta imprescindible retener lo siguiente:

Si según Nietzsche la voluntad, en cuanto voluntad de poder, es el carácter fundamental de todo ente, al determinar la esencia de la voluntad no podemos invocar un ente determinado, ni un determinado modo de ser, para, a partir de allí, explicar la esencia de la voluntad [...]. La voluntad, no puede caracterizarse determinándola como una facultad, ya que la esencia de una facultad está fundada en la esencia de la voluntad en cuanto poder (Heidegger, 2017, 45). ${ }^{11}$

La voluntad de poder designa el despliegue no teleológico, y sin embargo, siempre orientado de fuerzas (Haar, 1993, 26). En este sentido puede

11 Y enseguida señala: «Si la voluntad de poder caracteriza el ser mismo, no queda nada como lo cual pueda determinarse aún la voluntad. Voluntad es voluntad; pero esta determinación, formalmente correcta, no dice ya nada. Y conduce fácilmente a error si se piensa que a la simple palabra le corresponde una cosa igualmente simple [...]. Notable, que el pensador para el cual la voluntad es el carácter fundamental de todo ente, diga: "la voluntad no existe". Pero Nietzsche quiere decir que no existe esa voluntad que se ha conocido y definido hasta ahora como facultad anímica y como aspiración general» (Heidegger, 2017, 46). 
considerarse como principio $^{12}$ — si todavía puede llamarse así- de orientación divergente y discordante, que no obstante implica persistencia, consistencia y coherencia. El rasgo distintivo de la voluntad de poder es precisamente querer ser más, lo que significa estar obligado a superarse sin cesar. El querer debe entenderse como afirmación permanente, autoafirmación:

Nietzsche dice: "voluntad de poder". Todo querer es un querer-ser-más. El poder mismo sólo es en la medida en que sea y mientras sea un querer-sermás-poder. En cuanto se interrumpe esta voluntad, el poder ya no es poder, aunque aún tenga a su merced a lo dominado. En la voluntad en cuanto querer-ser-más, en la voluntad en cuanto voluntad de poder se encuentra de modo esencial el acrecentamiento, la elevación; pues sólo en la continua elevación lo elevado puede seguir siendo elevado y seguir en lo alto (Heidegger, 2017, 64).

La voluntad de poder como concepto metafísico, expresa el querer como tal y no lo querido. Éste puede tomar la forma de la generación o degeneración, de lo activo o reactivo, de lo ascendente o descendente, pues lo que está en juego es el querer mismo y éste puede pronunciarse tanto en el modo del esplendor como en el de la decadencia. En efecto: «la voluntad es en sí creadora y destructiva al

12 Si Heidegger acertó al afirmar que las preguntas de la filosofía, a diferencia de las científicas, en la medida en que se dirigen a lo esencial, siempre son las mismas, de manera que cuando la filosofía se mueve en círculos es señal de que ha logrado llegar a ese ámbito fundamental, entonces es posible afirmar que la voluntad de poder tiene carácter de «principio». En este marco de comprensión hacemos mención a lo dicho por Aristóteles a propósito de esta noción. Las seis acepciones de principio que propone señalan que principio es lo primero a partir de lo cual algo es, o se produce, o se conoce. De tal forma principio es: «1) el extremo de una cosa a partir del cual puede uno comenzar a moverse [...]; 2) y aquello a partir de lo cual cada cosa puede realizarse mejor [...]; 3) y lo primero a partir de lo cual se hace algo, siendo aquello inmanente "en esto" [...]; 4) y lo primero a partir de lo cual se hace algo, no siendo aquello inmanente "en esto" [...]; 5) y aquello por cuya voluntad se mueve lo que es movido y cambia lo que es cambiado [...]; 6) Además, se dice también que es principio "de una cosa" lo primero a partir de lo cual la cosa resulta cognoscible”". Y ciertamente lo común a todo tipo de principios es ser lo primero a partir de lo cual algo es, o se produce, o se conoce (Aristóteles, 1994, 1012b 35, 1013a 5-20). 
mismo tiempo. Dominar-más allá-de-sí es siempre también aniquilar» (Heidegger, 2017,67). ${ }^{13}$

Que todo querer sea en esencia querer ser más, implica ciertamente autoafirmación, pero no debemos ignorar que toda afirmación lleva ya consigo negación; en todo lo afirmado hay ya siempre algo negado. Por consiguiente, que la voluntad de poder exprese el carácter constitutivo del ser significa: todo ser es afirmación, persistencia, actualidad, pero a la vez negación y desistimiento.

\section{3. «EI "ser": no tenemos de él otra representación más que "vivir" »"14}

Ahora bien, para Nietzsche la vida es una expresión fundamental de la voluntad de poder que, sin embargo, no es la única. Aunque estaríamos tentados a identificar sin más estas dos nociones, ya que la «vida es la forma del ser que nos es más conocida» (Heidegger, 2017, 73), es importante recordar que la vida es sólo un caso particular de la voluntad de poder. La voluntad de poder entendida en términos de fuerza es, digámoslo así, previa a lo orgánico e inorgánico. ${ }^{15}$

13 «En la destrucción se pone lo que repugna, lo feo y lo malo; esto forma parte necesariamente del crear, es decir de la voluntad de poder y por lo tanto del ser mismo. De la esencia del ser forma parte lo nulo, no en el sentido de la mera nada del vacío sino en cuanto "no" que ejerce poder» (Heidegger, 2017, 65). A propósito de este doble movimiento que no deja de ser un querer, Michel Haar señala la siguiente paradoja: «Si tout vouloir signifie vouloir être plus fort, si toute puissance est sur puissance, le vouloir peut tenter de se dérober à lui même, a son exigence d'accroissement. Il y a là un paradoxe. Car en toute rigueur, cesser de "vouloir" est impossible: ce serait cesser d'être. La volonté décadente qui refuse: "d'admettre les conditions fondamentales de la vie" n'en reste pas moins une volonté: "L'homme préfère encore avoir la volonté du néant plutôt que de ne point vouloir du tout". Seule la direction du vouloir est inversée: l'accroissement devient progres dans la décadence» $(1993,27)$.

14 Heidegger $(2017,73)$.

15 La vida es un caso eminente, pero no único, de la voluntad de poder. No hay en Nietzsche una exaltación total de la vida, por el contrario, podemos encontrar en su pensamiento una rehabilitación de lo inorgánico que nos permite ver que antes de la distinción entre orgánico e inorgánico está la voluntad de poder entendida en términos de fuerza. En este sentido, Nietzsche afirma: «Donde hay vida, también hay voluntad: pero no voluntad de vida, sino — así te lo enseño yo — ¡voluntad de poder! Hay muchas cosas que el viviente estima más que la propia vida; pero a través de la estimación misma habla —ila voluntad de poder!» (Nietzsche, 2016b, 141). «Los fisiólogos deberían pensárselo bien antes de afirmar que el instinto de autoconservación es el instinto cardinal de un ser orgánico. Algo vivo quiere, antes que nada, dar libre curso a su fuerza; la autoconservación es tan sólo una de las consecuencias indirectas y más frecuentes de esto» (Nietzsche, 2016c, 305). «La voluntad 
La vida, caso paradigmático de la voluntad de poder, hace patente ese retraimiento fundamental que a ojos de Heidegger compete al ser y "recuerda" al olvido. De manera privilegiada, la vida del animal da cuenta de este retraimiento ontológico. Quizá por ello, al comienzo de la Segunda consideración intempestiva Nietzsche evoca la figura del rebaño para afirmar que la condición de la acción y la felicidad es el olvido. ${ }^{16}$

Observa el rebaño que ante ti desfila apacentándose: no sabe lo que es ayer ni lo que es hoy, corre de un lado a otro, come, descansa, hace la digestión, vuelve a correr, y así de la mañana a la noche, día tras día, atado a muy poca distancia con su placer y desplacer a la estaca del momento y, por ello, sin melancolía ni hastío. Ver esto le resulta duro al ser humano porque ante el animal se jacta de su humanidad "Menschentum" y, sin embargo, mira envidioso la felicidad de éste — pues lo único que quiere es vivir de igual modo que el animal, sin hastío ni dolores, pero lo quiere en vano porque no lo quiere como el animal. Un día el ser humano le pregunta al animal: "¿Por qué no me hablas de tu felicidad y, en cambio, te limitas a mirarme?». Y el animal quisiera responder y decir: «Eso pasa porque siempre olvido al punto lo que quería decir», pero ya olvidó también esa respuesta y se calló: de suerte que el ser humano se quedó asombrado. Pero se asombró también de sí mismo por no poder aprender a olvidar y seguir dependiendo siempre del pasado: por muy lejos y muy rápido que corra, la cadena corre con él (Nietzsche, 2011, 697).

\footnotetext{
de acumular fuerza como específico para el fenómeno de la vida, para la nutrición, la reproducción, la herencia, para la sociedad, el Estado, las costumbres, la autoridad [...] ¿ no deberíamos tener el derecho de admitir esta voluntad como causa motora incluso en la química?, ¡y en el orden cósmico? [...] no meramente constancia de la energía: sino economía maximal del consumo: de manera que el querer-llegar-a-ser-más-fuerte por parte de todo centro de fuerza es la única realidad, —no autoconservación, sino apropiación, querer-llegar-a-dominar, querer-llegar-a-ser-más, querer-llegar-a-ser-más-fuerte» (Nietzsche, 2015, 535). Sobre la no identificación de vida y voluntad de poder, véase Haar (1993, 171-172).

16 A propósito del pensamiento nietzscheano de madurez sobre el olvido, véase De la genealogía de la moral: «ésa es la utilidad, como decía, de la desmemoria activa, ser guardiana de la puerta y, como quien dice, conservadora del orden anímico, de la tranquilidad, y la etiqueta: con lo cual se ve de inmediato hasta qué punto sin esa desmemoria no podría haber felicidad ni buen humor ni esperanza ni orgullo ni presente alguno» (Nietzsche, 2016d, 484).
} 
Sin dejar de advertir la ambigüedad que caracteriza el modo de tratamiento nietzscheano sobre el olvido, en su lectura de la Segunda consideración intempestiva, Heidegger recoge algunas de las frases iniciales que arrojan luz acerca de los rasgos fundamentales de dicho fenómeno y emprende una sucinta descripción fenomenológica que nos llega en forma de notas de curso. Como lo muestra el ejemplo del rebaño, el olvido ancla en el presente, y sin decir nada, rompe los lazos que atan al pasado, ofreciendo una suerte de noticia muda sobre él. Así, el olvido alude a un tipo de relación que en sentido estricto no lo es, porque aquello hacia lo que tiende se ha desvanecido y se aleja. Olvidar, afirma Heidegger, es una forma pervertida de relación $(2003,44),{ }^{17}$ en la medida en que justamente no lo es. Se trata de una forma destacada de desprendimiento y pérdida, y por ello una remarcable no relación $(2003,45-46) .{ }^{18}$

La descripción sobre el olvido que Heidegger emprende a partir de Nietzsche le permite volver a la reflexión sobre el animal, que tuvo lugar en sus cursos de 1929-1930. ${ }^{19} \mathrm{~A}$ raíz de la pregunta sobre el modo de olvido que compete al animal y su diferencia esencial con el hombre, se desprenden caracteres importantes sobre este fenómeno que es necesario destacar:

[El olvido] como algo que se esfuma, que se escapa [...], ya sea porque no queremos retenerlo o porque nos hemos movido a algo más, porque lo hemos perdido de vista o porque está fuera de la mente [...]. El olvido como lo ya no pensado: como aquello en lo que ya no estamos, un no regresar, u olvidarse de uno mismo [...]. Cualquier movimiento de alejamiento y abandono» (Heidegger, 2003, 34-36).

A partir del ejemplo del animal, Nietzsche establece un vínculo entre vida, felicidad y olvido que, retrotraído al ámbito de lo ontológico, supone una

\footnotetext{
17 «Wenn somit das Vergessen eine Ab-und Unart des Behaltens ist, dann liegt im Vergessen ein Unbezug zum Seienden, ein Unverhalten, somit ein Sich-nicht -verhalten zum Seienden, welches Nicht-Verhalten nicht Nichts ist, sondern ganz im Gegenteil» (Heidegger, 2003, 44).

18 «Dieser Unbezug aber nicht notwendig als Bezug auf Vergangenes und gar als ein solches geeignet. Un-bezug und Bezugslosigkeit (wie etwa beim Stein) verschieden» (Heidegger, 2003, 45-46).

19 Ya que la pregunta central de este trabajo gira en torno al vínculo entre voluntad de poder, vida y olvido, y no acerca de la animalidad del animal, no nos detendremos en las consideraciones de Heidegger sobre dicha cuestión en los cursos citados.
} 
comprensión dilatada de éste. Lo que esta expresión sugiere es que la vida lleva consigo una suerte de olvido constitutivo que, en el modo de la autoafirmación, se manifiesta como exclusión y abandono de todo aquello que no sirve para su conservación y crecimiento. Así, por ejemplo, en cada instante de la vida animal podemos constatar esta afirmación que requiere de una "retracción" profunda. Cuando el animal caza o descansa, cuando come o duerme, cuando juega, la vida se hace patente en esta concentración selectiva que deja fuera todo lo que no sea necesario para su autoafirmación (Heidegger, 2007, 291-292).

La imagen apacible del rebaño que Nietzsche nos ofrece emerge como un destello de ese arraigo a la vida que implica un retraimiento fundamental. El olvido, como conditio sine qua non de la vida, tiene como fin la autoafirmación que se logra a partir de un movimiento de negación, desistimiento y retraimiento a la vez. Esta autoafirmación es un modo de exclusión, ya que en el olvido hay algo que, ciertamente, se deja fuera, se descarta, se rechaza o se abandona. Parecería que es la vida misma la que necesita este olvido originario. En todas sus formas, la vida, para poder vivirse, exige el olvido. Y quizá, precisamente ahí radica la mayor de las injusticias.

Esta suerte de recogimiento propio de la vida, en el que se extrae de la naturaleza todo lo que sirve para la conservación y crecimiento, constituye en sí mismo un horizonte que delimita, comprende y contiene todo aquello que resulta de provecho para sí, por eso Nietzsche afirma:

Se trata de una ley universal: todo ser viviente sólo dentro de un horizonte puede alcanzar salud, fuerza, y fecundidad; si es incapaz de encerrarse dentro de un horizonte y, por otra parte, demasiado egoísta como para integrar la propia perspectiva en otra ajena, decae, lánguido y afiebrado, y sucumbe prematuramente $(2011,699) .{ }^{20}$

20 Las cursivas son nuestras. En sus apuntes, Heidegger subraya el vínculo entre los términos horizonte y perspectiva, de importancia fundamental en el pensamiento posterior de Nietzsche. Horizonte aparece como delimitación, limitación, consolidación de la vida: "Vgl. Nietzsches späterer Begriff der "Perspektive" entsprechend der Überlieferung und dem Wortlaut; Horizont: Begrenzung, Einschränkung, Sicherung und Festigung des "Lebens”. Der Horizont nicht so sehr gefügemäßig als vielmehr lebensmäßig- im Bilck auf die Verlebendigung des Lebens -macht es "stark", "gesund", "fruchtbar" [...] (daher Horizont selbst wieder enger und weiter!)»(Heidegger, 2003, 137). En nota a pie, Joan B. Llinares, traductor de La 
Con el término horizonte —en griego horos, que significa "mojón", "límite", "frontera" (Adrián, 2009, 114)—, ${ }^{21}$ se expresa ese margen que los seres vivos necesitan para vivir. La idea de límite no refiere aquí a un tipo de fin o conclusión, tampoco a un confinamiento. Por el contrario, sugiere que la asimilación e integración de lo otro le son propios también al movimiento de ensimismamiento o abstracción. Así, el fenómeno de la alimentación aparece como emblemático: «Eso que llamamos vida es una pluralidad de fuerzas ligadas por un fenómeno de nutrición que les es común» (Haar, 1993, 177).$^{22}$ El fenómeno de la nutrición, comprendido como una suerte de interpretación, nos permite observar que esta interpretación es elevada a rango vital, y por ende, ontológico. En efecto, para realizar la nutrición, el ser orgánico debe ser capaz de sensibilidad, de apetito, pero sobre todo de evaluación, elección, asimilación y eliminación, por lo tanto, de pensamiento. De tal suerte, la nutrición, como fenómeno de incorporación, presupone no sólo la interpretación y la selección, sino también la memoria (Haar, 1993, 177). ${ }^{23}$

segunda consideración intempestiva, escribe: «La delimitación que el horizonte establece es aquello mediante lo que un individuo, un pueblo o un organismo decide lo que es útil o nocivo para su desarrollo. Es decir, todo ser vivo interpreta lo existente a partir de lo que se le presenta en su propio horizonte» (Nietzsche, 2011, 699).

${ }_{21}$ Es interesante mencionar que el sentido que retomamos del término horizonte se vincula en particular con los trabajos de Jakob von Uexküll dedicados a la biología, determinante en el pensamiento heideggeriano de Los conceptos fundamentales de la metafísica. Mundo, finitud y soledad. El término Umwelt, propuesto por Uexküll para describir el mundo del animal, expresa de manera singular el sentido de horizonte al que hemos aludido.

22 A propósito de la nutrición como fenómeno emblemático de incorporación, Nietzsche afirma en De la genealogía de la moral: "[la desmemoria] no es una mera vis inertiae, como suelen creer los insustanciales, sino, por el contrario, una capacidad de inhibición activa, positiva, en el sentido más riguroso del término, a la que se ha de atribuir el que de todo lo vivido, lo experimentado por nosotros, de todo lo recibido penetre en nuestra conciencia en la fase de digestión (podría llamarse "inspirituación") tan poco como penetra en ella del multiforme proceso entero con que se realiza la alimentación de nuestro cuerpo, la llamada "incorporación”» (2016d, 484). Y más adelante señala: "Cuando alguien no logra arreglárselas con un "dolor psíquico", no es, dicho burdamente, por causa del "alma”; es más probable que sea del vientre [...]. Un hombre fuerte y bien constituido digiere sus comidas, aun cuando tenga que tragar bocados difíciles. Si "no consigue arreglárselas" con una experiencia, la indigestión consiguiente es tan fisiológica como aquella otra - y muchas veces de hecho sólo una de las consecuencias de aquella otra. -Aun viendo así las cosas, se puede seguir siendo, dicho sea entre nosotros, el más severo enemigo del materialismo" (2016d, 537).

23 «Justo ese animal por fuerza olvidadizo, en el que olvidar representa una fuerza, una forma robusta de salud, ha cultivado en sí una facultad opuesta, una memoria con cuya ayuda la desmemoria queda en algunos casos en suspenso - en concreto en aquellos casos en que toca hacer una promesa; así pues, no es para nada un mero-no-poder-deshacerse de la palabra empeñada a alguien en alguna ocasión, con la que uno no sabe qué hacer, sino de un 


\section{La condición de la acción es el olvido}

Ahora bien, que la vida requiere del olvido en todas sus formas, lo muestran no sólo sus funciones más elementales sino también las más complejas. En el orden de la psique, el olvido se ejerce como una función selectiva, ya sea consciente o inconsciente, que tiene como propósito desalojar de la conciencia aquello que resulta incómodo o doloroso para poder seguir viviendo. ${ }^{24}$ En el ámbito de la acción, Nietzsche será enfático al afirmar:

En toda acción hay olvido: del mismo modo que en la vida de todo ser orgánico hay no solamente luz, sino también oscuridad. Un ser humano que quisiera por entero sentir solamente de forma histórica se parecería a uno que estuviera obligado a prescindir del sueńo, o a un animal que tuviera que subsistir exclusivamente a base del siempre renovado rumiar. En consecuencia: es posible vivir, y aun vivir feliz, casi sin recordar, como lo muestra el animal; pero es totalmente imposible vivir sin olvidar $(2011,698) .{ }^{25}$

\footnotetext{
no-querer-deshacerse activo, un volver a querer una y otra vez lo que una vez se ha querido, una auténtica memoria de la voluntad» (Nietzsche, 2016d, 485).

24 El psicoanálisis representa un hito determinante en la concepción del olvido, en efecto: «Con Freud, el olvido ha perdido su inocencia [...]. Para Freud, todo olvido tiene una razón [...] el motivo universal que, sospecha, está detrás de todos los casos individuales de olvido y hay que buscar tercamente y sacar a la luz en el tratamiento psicoanalítico como "intención secreta del que olvida”, es el motivo del malestar (Unlust). Olvido gustosa y fácilmente lo que me resulta desagradable, irritante, embarazoso, lo que atormenta mi conciencia, y alcanzo de este modo mi objetivo psíquico: "evitar el malestar". Es sabido que Freud califica como represión (Verdräng) precisamente esta acción del malestar que tanto fomenta el olvido» (Weinrich, 1999, 224-225).

25 Respecto de la necesidad del olvido para la acción, dice Nietzsche: «Todo animal y, por lo tanto, también la bête philosophe, tiende instintivamente a lograr un optimum de condiciones favorables en las que pueda descargar por completo su fuerza y logre un maximum de sentimiento de poder; todo animal, de manera asimismo instintiva y con un olfato de una finura que "es más elevada que la razón", aborrece todo tipo de perturbadores y de obstáculos que se le pongan o se le puedan poner en el camino a ese optimum (... no es del camino a la "felicidad" de lo que estoy hablando sino de su camino al poder, a la acción, al hacer más poderoso, y, en la mayoría de los casos, el camino de hecho a la infelicidad)» (2016d, 521). En otro lugar, señala: "Cerrar de vez en cuando las puertas y ventanas de la conciencia; no verse molestado por el ruido y la lucha con que ese submundo nuestro de órganos de servicio despliega su labor de colaboración y oposición; lograr un poco de silencio, de tabula rasa en la conciencia, para que vuelva a haber sitio para lo nuevo» (2016d, 484).
} 
De tal forma, no es en la luz de la conciencia ni en la claridad del pensamiento donde la acción encuentra su origen, sino en un mar muerto de noche y olvido:

Es éste el estado más injusto del mundo, estrecho, desagradecido con lo pasado, ciego a los peligros, sordo a las advertencias, un pequeño torbellino viviente en un mar muerto de noche y olvido: $y$, sin embargo, este estado —absolutamente ahistórico — es la matriz, no ya de una acción injusta, sino de todas las acciones justas; y ningún artista logrará la imagen de su creación, ningún jefe militar su victoria, ningún pueblo su libertad, sin haberla antes deseado y anhelado en tal estado ahistórico (Nietzsche, 2011, 700).

El estado más injusto ${ }^{26}$ anunciado por Nietzsche quizá radica precisamente en esta exclusión y abandono que exige toda acción y que revela la necesidad de seguir para no sucumbir a la muerte. Ésta es la injusticia: dejar atrás. No atarse al recuerdo que reclama fidelidad. Del apego al recuerdo, sin duda da cuenta la nostalgia, un temple de ánimo que Nietzsche no pretende cultivar.

De esta manera, es posible afirmar que dependerá del olvido el grado de fuerza plástica de un ser humano, un pueblo, una cultura. Su fuerza para desarrollarse específicamente a partir de sí mismo, de transformar y asimilar lo pasado y lo extraño, de cicatrizar heridas, de reponer lo perdido, de regenerar formas destruidas (Nietzsche, 2011, 698). Y es que, lo que una tal naturaleza no logra dominar, afirma Nietzsche, lo sabe olvidar $(2011,30)$ :

Así como el agente, según la expresión de Goethe, siempre carece de conciencia, carece siempre también de ciencia, olvida la mayor parte de las cosas para hacer una sola, es injusto con lo que queda atrás y no reconoce

26 El concepto de justicia en Nietzsche, y la posterior lectura heideggeriana de éste, es de raigambre profunda y compleja. Así lo muestran los múltiples apartados que Heidegger dedica en sus apuntes sobre la Segunda consideración intempestiva. Ciertamente, el modo de aproximarnos a la cuestión de la justicia y la injusticia no obedece de manera puntual a este contexto. 
más que un solo derecho, el derecho de lo que en ese momento ha de ser. Así todo agente ama su acción infinitamente más de lo que ella merece ser amada: y las mejores acciones se llevan a cabo en un arrebato de amor tal que, desde luego, no valen este amor, por incalculable que, por lo demás, sea su valor $(2011,700)$.

Ese estado ahistórico ${ }^{27}$ anunciado por Nietzsche aparece como una suerte de origen que precede a toda acción y que de alguna manera se identifica con la vida. En efecto: «[lo ahistórico] semeja una atmósfera envolvente que es la premisa de la vida, extinguiéndose ésta se queda destruida aquella» $(2011,699)$. Esta atmósfera envolvente, ahistórica, premisa de la vida, no tiene carácter de causa, porque de ella no se sigue efecto alguno, tampoco refiere a un tipo de proceso o génesis. Sin embargo, es origen porque tiene carácter de principio ${ }^{28}$ en la medida en que alude a ese ámbito primero, originario, a priori ${ }^{29} \mathrm{y}$ constitutivo, ${ }^{30}$ que acompaña siempre, como una sombra. El sentido que propone Heidegger sobre origen

27 Como es sabido, uno de los propósitos de la Segunda consideración intempestiva es pensar en la relación de la historia con la vida, de la cual deriva el análisis sobre lo ahistórico y la consideración de los distintos modos de hacer historia, los cuales exceden los límites de la propuesta aquí tratada.

28 A propósito de la relación entre principio y causa, Tomás Calvo, traductor de la Metafísica de Aristóteles, señala: «La relación entre los términos arché (principio) y aítion (causa) es vacilante en Aristóteles, al igual que en la lengua común. A menudo tienden a coincidir extensionalmente, aun cuando cada uno de ellos posee un rasgo peculiar del que el otro carece: "causa" suele comportar la idea de influjo; "principio" comporta la idea de orden y prioridad en éste (cf. Aquino, 751). Como consecuencia de estas diferencias, a) a veces se considera más amplia la noción de principio que la de causa: toda causa es principio, pero no todo principio es causa (el punto de partida de un trayecto es su principio, y así lo recoge Aristóteles en la primera de las acepciones propuestas, pero nadie lo consideraría causa del trayecto), b) mientras que otras veces se considera más amplia la noción de causa: no todas las causas son principios, solamente lo son las causas primeras» (Aristóteles, 1994, 206-207).

29 El sentido del término a priori que nos interesa destacar es justo aquel que es posible vincular a la noción de principio en el sentido de anterioridad no cronológica, de tal manera es posible afirmar: "Que eso "ha de ser posible a priori" significa que tiene una determinada constitución, naturaleza, forma, possibilitas, la cual es a priori con respecto a todo contenido de eso mismo [...], a priori (como) una cierta possibilitas, constitución, esencia, naturaleza, forma» (Martínez Marzoa, 1989, 26). Así, de acuerdo con la tesis que hemos propuesto, afirmar que lo histórico tiene su origen en lo ahistórico quiere decir que en este ámbito, no susceptible de historiar, encuentra su possibilitas, su constitución, su forma. Y este a priori, en tanto que elemento suyo, no queda atrás, sino que lo acompaña siempre.

30 La noción de elemento, en el propio Aristóteles, vale para comprender el carácter constitutivo que queremos subrayar. Sobre dicha noción, dice el filósofo: «Se llama elemento [...] lo 
recoge las distintas acepciones del término que nos interesa subrayar: «Origen significa [aquí] aquello a partir de donde y por lo que una cosa es lo que es y tal como es. Eso que algo es y cómo es, es lo que llamamos su esencia. El origen de algo es la fuente de su esencia» $(2016,19)$.

En tanto que origen, lo ahistórico nunca queda atrás; no alude a un tiempo susceptible de ser datado y tampoco a un ámbito trascendental. El estado ahistórico al que refiere Nietzsche puede entenderse como inmemorial, esto es, como lo que escapa en definitiva a la memoria y al recuerdo. En este sentido, es posible calificarlo como el olvido más puro, aquel que no encuentra en la memoria su contraparte y por ello de ninguna manera puede hacerse disponible y volverse objeto de recuerdo, ya que inmemorial es:

Lo que nunca constituyó acontecimiento para mí y lo que incluso nunca adquirimos realmente, lo que incluso es menos formal que ontológico. En el fondo del fondo, tendríamos el olvido de los fundamentos, de sus donaciones originarias, fuerza de vida, fuerza creadora de historia, Ursprung, "origen", en cuanto irreductible al comienzo, origen siempre presente (Ricoeur, 2004, $564) .{ }^{31}$

\section{A modo de conclusión: el olvido profundo}

En todas sus formas, el olvido lleva consigo una suerte de exilio o extrañamiento que se manifiesta con matices y niveles diversos, así, afirma Heidegger, el olvido más profundo ocurre en el más alto y más constante retener (y mantener), ${ }^{32}$ como lo que por lo general y precisamente no se hace presente. En este sentido, no es más un desvanecimiento, un pasar por alto o un dejar ir $(2003,47) .{ }^{33}$

primero de-lo-cual algo se compone, siendo aquello inmanente (en esto) y no pudiendo descomponerse, a su vez, específicamente en otra especie distinta» (1994, 1014a, 23-26).

31 Las cursivas son nuestras.

32 «Die tiefste Vergessenheit dort, wo das ständigst und vor allem Anderen Behaltene (und Haltende), und wo dieses das überhaupt Haltgebende, gerade nicht vergegenwärtigt wird (die Zugehörigkeit in die Wahrheit des Seins)»(Heidegger, 2003, 47).

33 «Dieses Vergessen kein Entfallen, kein Verlieren; das Sein wird ja stets verstanden» (Heidegger, 2003, 47). 
En efecto, si de acuerdo con lo hasta aquí pensado, olvidar, en sentido ordinario, sólo puede tener lugar sobre la base del retener. Y retener debe comprenderse como un modo de tener ante-uno-mismo (Heidegger, 2003, 38-39). ${ }^{34}$ En el olvido esencial, el "orden" se ha invertido, de tal forma que todo olvido ordinario es posible, primero que nada, sobre la base del olvido originario (2003, 47). ${ }^{35}$ Olvido que a lo largo de este texto hemos propuesto como principio y al que Heidegger se refiere como el más abismal y cuestionable (2003, Heidegger, pp.42). ${ }^{36}$

Al comienzo de este trabajo, seguimos a Heidegger en el ejercicio deconstructivo del término olvido y vimos la íntima conexión que el filósofo encuentra con la palabra alétheia. Aunque en principio ambos vocablos parecerían ajenos, advertimos la negatividad estructural que los determina y vincula, negatividad que debe comprenderse como propia del ser en la medida en que:

La verdad se encuentra junto con el ser en el ámbito de la pregunta fundamental no porque se dude de la posibilidad de la verdad en un sentido gnoseológico, sino porque pertenece ya a la esencia de la pregunta fundamental en un sentido señalado, como su "espacio". En la pregunta fundamental y en la pregunta conductora, en las preguntas acerca del ser y acerca del ente, también se pregunta, al mismo tiempo y en lo más hondo, por la esencia de la verdad (Heidegger, 2017, 71).

El olvido así considerado hace patente su conexión íntima con la comprensión del ser como voluntad de poder. En efecto, el olvido del ser - Seinsvergessenheit- entendido como el más profundo retener y mantener, encuentra eco en la voluntad de poder comprendida como conservación y aumento. La retención, traducida como conservación, debe entenderse como autoafirmación, ya que la voluntad de poder, «no sólo tiene el impulso de autoconservarse, sino que es

34 «Das "Behalten” in der Weise des Vor-sich-habens. Vor-stellen-können als ein "Gegenwärtiges” und zwar Vergegenwärtigenkönnen. Gegenwärtig: im Umkreis des gerade Vorgestellten» (Heidegger, 2003, 39).

35 "Alles gewöhnliche Vergessen erst möglich auf dem Grunde einer ursprünglichen Vergessenheit» (Heidegger, 2003, 48).

36 "[...] die (abgründigste) und fragwürdigste Vergessenheit» (Heidegger, 2003, 42). 
autoafirmación» (Heidegger, 2017, 65), «es ella misma la originaria afirmación esencial» $(2017,65)$, que debe comprenderse como permanente incremento de sí. Este acrecentamiento, que implica autoafirmación y se refiere al ser y a la esencia del ente (Heidegger, 2017, 65), tiene, a ojos de Heidegger, un carácter eminentemente creador. En este sentido, afirma:

Aunque Nietzsche no lo formule así expresamente, en el fondo piensa esto; de otro modo no sería comprensible aquello a lo que siempre alude en conexión con la acentuación del carácter de acrecentamiento que posee la voluntad, de su "plus de poder": que la voluntad es poder creador. Con esta afirmación no se pretende sostener que la voluntad de poder y por su intermedio debiera producirse algo, lo decisivo no es el producir en el sentido de fabricar, sino el sacar fuera y transformar, ese ser diferente que..., y diferente en un sentido esencial $(2017,65)$.

Así las cosas, la afirmación incesante propia de la voluntad de poder, que cada vez y en cada caso implica incremento de sí, supone una suerte de repetición, esto es, de retorno, que de manera paradójica será entendido como transfiguración. De tal forma, para Nietzsche, y sin duda también para Heidegger, el arte será el lugar emblemático de afirmación, y por ende, de verdad. En efecto, por medio de un proceso de selección, incorporación y asimilación, el arte logra la transfiguración misma de lo real. Transfiguración que pone en obra, esto es, hace manifiesta la esencia de lo que es (Leyte, 2008, 30-31). Así, la vida, como la entiende Nietzsche y la distingue Heidegger, procede del mismo modo que el arte y el artista. En este sentido, puede ser comprendida como obra que, para llevarse a cabo, necesita del olvido. 


\section{Bibliografía}

Adrián Escudero, J. (2009). El lenguaje de Heidegger. Diccionario filosófico 1912-1927. Barcelona: Herder.

Aristóteles. (1985). Ética nicomáquea. Madrid: Gredos. Julio Pallí Bonet (trad.). (1994). Metafísica. Madrid: Gredos. Tomás Calvo Martínez (trad.).

Aspiunza, J. (2016). "Prefacio". En F. Nietzsche, Obras completas. Vol. 4: Escritos de madurez II y complementos a la edición (pp. 441-452). Madrid: Tecnos.

HaAr, M. (1993). Nietzsche et la métaphysique. París: Gallimard.

Heidegger, M . (1977). Gesamtausgabe, Vol. 5: Holzwege. Frankfurt am Main: Vittorio Klosterman. F.-W. von Herrmann (ed).

(1992). Gesamtausgabe, Vol. 29/30: Die Grundbegriffe der Metaphysik. Welt-Endlichkeit-Einsamkeit (WS 1929/30). Frankfurt am Main: Vittorio Klosterman: F.-W. von Herrmann (ed.).

(1996). Gesamtausgabe. Vol. 6.1 Nietzsche I (1936-1939). Frankfurt am Main: Vittorio Klosterman. Brigitte Schillbach (ed).

(2003). Gesamtausgabe. Vol. 46: Zur Auslegung von Nietzsches II. Unzeitgemässer Betrachtung. Frankfurt am Main: Vittorio Klostermann. Hans-Joachim Friedrich (ed).

(2007). Los conceptos fundamentales de la metafisica. Mundo, finitud, soledad. Madrid: Alianza. Alberto Ciria (trad.).

. (2016). El origen de la obra de arte. Madrid: La Oficina. Arturo Leyte (trad.).

(2017). Nietzsche. Barcelona: Ariel. J. L. Vermal (trad.).

LeYte, A. (2005). Heidegger. Madrid: Alianza.

(2007). "Heidegger: la metafísica del Dasein". En J. J. García y R. Rodríguez (eds.), Cómo se comenta un texto filosófico (pp. 169-187). Madrid: Síntesis.

(2008). "Introducción”, en M. Heidegger, Identidad y diferencia (pp. 7-54).

Barcelona: Anthropos.

Martínez Marzoa, F. (1989). Releer a Kant. Barcelona: Anthropos.

Nietzsche, F. (2011). Obras completas. Vol. 1: De la utilidad y los inconvenientes de la historia para la vida. Segunda consideración intempestiva. Madrid: Tecnos. Joan Llinares, Diego Sánchez Meca y Luis E. de Santiago (trads.).

(2015). Fragmentos póstumos (1885-1889). Vol. IV. Madrid: Tecnos.

. (2016a). Obras completas. Vol. 4: Escritos de madurez II y complementos a la edición. Madrid: Tecnos.

ÉNDOXA: Series Filosóficas, n. 43, 2019, pp. 227 -247. UNED, Madrid 
(2016b). Asi habló Zaratustra. En F. Nietzsche, Obras completas. Vol. 4: Escritos de madurez II y complementos a la edición (pp. 65-279). Madrid: Tecnos.

. (2016c). Más allá del bien y del mal. En F. Nietzsche, Obras completas. Vol. 4: Escritos de madurez II y complementos a la edición (pp. 283-437). Madrid: Tecnos.

(2016d). De la genealogía de la moral. En F. Nietzsche, Obras completas. Vol. 4: Escritos de madurez II y complementos a la edición (pp. 441-560). Madrid: Tecnos.

Ricoeur, P. (2004). La memoria, la historia, el olvido. Buenos Aires: Fondo de Cultura Económica. Agustín Neira (trad.).

Volpi, F. (1988). "Dasein comme praxis: l'assimilation et la radicalisation heideggerienne de la philosophie practique d'Aristote”. En F. Volpi (ed.), Heidegger et l'idée de la phénomenologie (pp. 1-42). Dordrecht: Kluwer Academic Publishers.

. (2007). El nihilismo. Madrid: Siruela.

. (2012). Heidegger y Aristóteles. México: Fondo de Cultura Económica. María Julia de Ruschi (trad.).

Weinrich, H. (1999). Leteo. Arte y critica del olvido. Madrid: Siruela. Carlos Fortea (trad.).

Recibido: 29/09/2017

Aceptado: 7/09/2018

Este trabajo se encuentra bajo una licencia de Creative Commons Reconocimiento-No Comercial-Sin Obra Derivada 4.0.

ÉNDOXA: Series Filosóficas, n. 43, 2019, pp. 227 - 247. UNED, Madrid 
